\title{
A pastoral evaluation of menopause in the African context
}

\begin{tabular}{|c|c|}
\hline \multicolumn{2}{|l|}{$\begin{array}{l}\text { Author: } \\
\text { Elijah Baloyi }^{1}\end{array}$} \\
\hline \multicolumn{2}{|c|}{$\begin{array}{l}\text { Affiliation: } \\
{ }^{1} \text { Department of Practical } \\
\text { Theology, University of South } \\
\text { Africa, South Africa }\end{array}$} \\
\hline \multicolumn{2}{|c|}{$\begin{array}{l}\text { Note: } \\
\text { This article is published in the } \\
\text { section Practical Theology of } \\
\text { the Society for Practical } \\
\text { Theology in South Africa. }\end{array}$} \\
\hline \multicolumn{2}{|c|}{$\begin{array}{l}\text { Correspondence to: } \\
\text { Elijah Baloyi }\end{array}$} \\
\hline \multicolumn{2}{|c|}{$\begin{array}{l}\text { Email: } \\
\text { baloye@unisa.ac.za }\end{array}$} \\
\hline \multicolumn{2}{|c|}{$\begin{array}{l}\text { Postal address: } \\
\text { PO Box 392, UNISA 0003, } \\
\text { South Africa }\end{array}$} \\
\hline \multirow{2}{*}{\multicolumn{2}{|c|}{$\begin{array}{l}\text { Dates: } \\
\text { Received: } 02 \text { Feb. } 2012 \\
\text { Accepted: } 05 \text { May } 2012 \\
\text { Published: } 15 \text { Jan. } 2013 \\
\text { How to cite this article: } \\
\text { Baloyi, E., 2013, 'Pastoral } \\
\text { evaluation of menopause } \\
\text { in the African context', } \\
\text { HTS Teologiese Studies/ } \\
\text { Theological Studies 69(2), } \\
\text { Art. \#1226, } 7 \text { pages. } \\
\text { http://dx.doi.org/10.4102/ } \\
\text { hts.v69i2.1226 }\end{array}$}} \\
\hline & \\
\hline \multicolumn{2}{|c|}{$\begin{array}{l}\text { Copyright: } \\
\text { (C) 2013. The Authors. } \\
\text { Licensee: AOSIS } \\
\text { OpenJournals. This wor } \\
\text { is licensed under the } \\
\text { Creative Commons } \\
\text { Attribution License. }\end{array}$} \\
\hline \multicolumn{2}{|l|}{ Read online: } \\
\hline 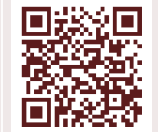 & $\begin{array}{l}\text { Scan this QR } \\
\text { code with your } \\
\text { smart phone or } \\
\text { mobile device } \\
\text { to read online. }\end{array}$ \\
\hline
\end{tabular}

Menopause, with its physical and emotional changes, appears to be an inevitable road for women to travel. The moment of choice for women at menopause involves not only whether they will embrace the new self or try to cling to identities from earlier life but also how the society in which they live views women after menopause. Amongst other things, many African marriages face difficulties when the moment of menopause arrives. This situation is often characterised by a second marriage or a situation where husband and wife no longer share a room. Whenever this happens, it testifies to the idea that the sole purpose of marriage amongst African people is procreation - hence, when the period for that is passed, the bedroom setup changes. This is one of the ways in which senior women are deemed unfit for sexual encounters, a gender-equality concern. This article aims to unveil and discuss how some Africans use menopause as an excuse to exclude women from sexual intercourse, and how pastoral caregivers can help in such situations.

\section{Introduction and problem statement}

On 18 June 2011, the author was a participant in the funeral of an old man, a pensioner turned shepherd, outside Malamulele Township. It was explained that the body of the deceased was found dead on the bed in the room which this married man used to occupy alone. They found him after it was discovered that his cattle did not come to the grazing fields that morning. I wanted to know why a married man's body was found so long after he had died. I felt that the first witness to the married man's death would surely have been his wife. This prompted me to investigate why a married man's body were found only after a long search. One elderly man, who did not wish his name to be mentioned, explained to me that it was because of the taboo on husbands and wives sleeping together after the onset of the female menopause. The deceased man was found alone because his wife used a separate room in observance of the taboo. This incident helped me realise that we still have many older married African couples who occupy separate rooms when the period of menopause arrives, citing similar reasons.

Furthermore, although many African people are known for their patriarchy, which has always oppressed women, it is clear that menopausal women were given a special place during the ancestral worship - a practice which was used to combat HIV and AIDS in Kenya. Gathogo (2007) says:

In times of drought and other calamities leading elders who were mainly men plus 'few menopausal women' summoned all the people to gather together for worship. When killing of the sacrificed animal, a boy or girl-child and 'a menopausal woman' would touch the animal's head while the elders slaughtered it. (p. 15)

The special role in the worship afforded exclusively to menopausal women signifies that, in the African context, menopausal women have been treated differently.

When trying to connect these incidents to the study of African scholars like Kyomo and Selvan (2004), Kimathi (1994) and Peil and Oyeneve (1998), I realised that this is one of the practices which has been ignored - if not neglected - by many African writers. This neglect resulted in some members of our society still being enslaved by the traditions and taboos which some of the African people have connected to menopause. This point of view is confirmed by Collins (2011:65): 'The socio-cultural aspects of menopause have not been the focus of attention or research interest to the same extent as menopause as a physiological event.'

After a thorough search in the libraries, I also realised that most written material on this topic was based on other cultures and countries like America. This means that it is an area that requires a great deal of work by African researchers. It was because of this and other similar unreported cases that I decided to study menopause, particularly in some of the African tribes (like Shangaans and other tribes with similar practices), in order to assist both pastoral caregivers 
and the community to gain a better understanding of menopause than what is currently held by some Africans.

According to Voda (1997:133), many women, the majority probably, suffer considerably during the transitional years of menopause. Although the symptoms tend to be organic and physical, the psychological symptoms predominate. There is an ancient mythology amongst some African people indicating that menopause is a sign that renders it forbidden for women to engage in sexual activities, and that myth is still evident in some African cultures today. Kimathi (1994) explains:

\begin{abstract}
Menopause among many ethnic groups brought an end to the need for sexual activities. A woman with married daughters and sons was regarded as somebody who had finished her sexual role in marriage. She now was considered too old for sexual encounters. This was something that was regarded as a duty for the younger wives. It is not surprising, therefore, that an older woman would tell her husband that it was time he got himself a new wife as an indication that she was ready for exemption from her sexual obligations. (p. 13)
\end{abstract}

This explains why some Africans would preclude their older women from having sexual intercourse. It would not be surprising for an older woman to tell her husband that it was time that he took a new wife, as an indication that she was ready to be exempted from her sexual obligations. As far as women are concerned, their role to procreate had been accomplished, so why then would they need sex at their age? This attitude did not in prevail only in the past but, according to Kimathi (1994:13), it is continuing among some married couples today.

According to Kyomo and Selvan (2004:35), many African people believe that a woman should not have sexual intercourse after menopause. The reason, according to the two writers above, is the belief that, if a woman breaks this taboo, she will be punished physically: Her stomach will grow bigger and bigger or else the seminal fluid accumulated in her stomach will flow out through her genital organ, leaving behind an unpleasant odour (Kyomo \& Selvan 2004:36). Amongst other reasons the Tsonga speaking people refer to this big stomach as xikuru-nyimba, this belief makes it very clear that every woman who engaged in sexual activities after menopause is risking her own health. In this way, many women voluntarily abstain from sexual encounters in order to preserve their own health.

Peil and Oyeneve (1998:35) also contend that, in some African contexts, marriage ends once the woman is past child-bearing age. That is why Baloyi (2011:4) argues that procreation has become the sole purpose of marriage amongst many African people (cf. Baloyi 2001:11-15). With this argument in mind, we can assume that, in some African contexts, sexual activities for women are limited to a particular and specific period. The truth is that, even amongst women themselves, menopause brings unexpected symptoms like emotional stress, sleep disturbances, feelings of grief, anxiety and other psychological challenges and disorders (King, Hunter \& Harris 2005:28). Taking this point of view, one can see that menopause is taken as another reason to undermine women. All of the above argues that it is for pastoral caregivers to investigate female menopause in order to reveal possible ways in which African people can approach menopause without the negative perceptions which might lead to divorce, polygamy or seeing the wife as no longer an important person in the house.

\section{Meaning and background}

It would be a good idea to start by defining what menopause is. Komesaroff, Rothfield and Daly (1997:17) argue that it is impossible to consider the meaning and experience of menopause without first exploring the socio-historical context that shapes the body as a particular form in which the experience of menopause is deemed to occur, or is prevented from occurring. Menopause means the end of menstruation periods for women. As a woman ages, there is a gradual decline in the function of her ovaries and the production of oestrogen. Around the time a woman turns 40, this process speeds up (http:/ / men.wemd.com/guide/male-menopause).

Gupta, Holloway and Kubba (2010:222) define menopause as the permanent cessation of menstruation that is caused by ovarian failure. Martin and Jung (2002:15) share the same opinion, calling menopause 'the permanent cessation of menstruation'. It is also advisable to consider a woman menopausal only when she has not had a menstrual period for at least a year (Eskin 2007:35). Besides the fact that it occurs in all women who live long enough, the period that leads up to menopause is called peri-menopause. Even though the medical community labels menopause an illness caused by a lack of hormones, some women tend to view menopause as merely a life event, or rite of passage, whilst others view it as an end to child-bearing potential (King et al. 2005:28). Although there is an argument that women may not be the only ones who suffer the effects of changing hormones in the form of menopause, this study will confine itself to menopause in females.

During this transition period, a woman's personality may be completely changed. From being gentle and submissive, she may become pugnacious and quarrelsome. Unfounded jealousy - which may well be one of the disagreeable symptoms - could make both wife and husband very unhappy (Voda 1997:113). The exact age of menopause is also difficult to pinpoint because of the many theories that people use to determine it. Some allude to the usual story, namely that women who started menstruating earlier than most will end later than most. Another theory holds that a woman will experience menopause at the same age as her mother did (Millette \& Hawkins 1983:36).

Although this theory would mean that it is hereditary, it raises questions like the following: What about one whose mother passed away before she reached menopause? How would this be observed? Another theory indicates that the 
length of time spent in breast-feeding babies or in pregnancy is also reputed to shorten the reproductive span, which means earlier menopause would occur for women who breast-fed their children (Millette \& Hawkins 1983:36). Even though some argue that menopause sets in at the age of fifty, the research emphasises that variation should still be considered because it does not bear out all the tales and theories.

\section{Varying attitudes towards menopausal transition}

Since women have different expectations of menopause, cultural background may also play a pivotal role in influencing a women's response to menopause. That is why Collins (2011) says:

Bowles emphasised that women's experience of and attitude towards menopause are influenced by beliefs and expectations inherent in the prevailing socio-cultural paradigm. Thus, factors such as cultural beliefs, values, and attitudes towards menopause determine the experience of individual women of that stage of life as negative and troublesome or positive and liberating. (p. 65)

Such a reaction is often affected by a woman's status in her own culture - whether she is valued or devalued. In cultures where women are given more status when they are beyond child-bearing age, women seem to have fewer problems with menopause. However, cultures in which women define themselves as primarily in a child-bearing role, they seem to experience most distress (King et al. 2005:30). The medical community views and labels menopause as 'an illness in search of hormones' (King et al. 2005:28). There is evidence that some people argue that menopause should be treated as a medical disease. Voda (1997:113) is of the opinion that Robinson would have been astonished to read in the medical literature of the 1990s that menopause is viewed by medicine either as an oestrogen-deficiency disease, or an endocrinopathy, rather than a normal process.

The statement above serves to confirm that, for some years, there was an ongoing debate between those who believed that menopause should be treated as a medical disease and those who did not. Although for many women, menopause signifies entering one of the healthiest and most balanced phases of their life, some women run an increased risk of heart disease after menopause (Martin \& Jung 2002:33). Whilst psychological distress has been seen to accompany an early or late menopause, some women have reported a loss of emotional balance during the changes to their menstrual patterns, which resulted in unsettling episodes of instability persisting for years after cessation (Komesaroff et al. 1983:161-162). It was in response to this medical view of menopause that Millette and Hawkins pointed to a number of resources for health, including obstetricians or gynaecologists who are available to help women deal with this situation. Some women in Western cultures view it as merely a life event or a rite of passage. In support of this view, Woods and Mitchel (in Millete \& Hawkins 1983:168) emphasise that it is a normal developmental process.

\section{An African view on menopause}

In order to understand the view of most African people on menopause, we need to trace it to the way they view child bearing in marriage. Nhlapo (1991:143) argues that many women in Africa are expected to become wives at some stage in their lives, and as wives, they are required to be first and foremost - mothers. In contrast, Burman (1991:36) maintains that the saying 'Cattle beget children' is very common and means that, once the bride price has been paid, the wife is expected to bear children. It should also be understood that, in some African contexts, it is the man or husband who determines how many children must be born which, in turn, determines how long sexual intercourse will continue in the family. Strictly speaking, it is the man who determines the size of the family: The woman has no say at all (Labeodan 2007:46).

According to Baloyi (2010:58), childlessness is regarded as an unacceptable situation which can easily lead to the marrying of a second wife, which entails polygamy. Labeodan (2007:45) argues that a barren woman is considered to be dead and useless to the community. This indicates that many Africans rate child-bearing as the highest priority for marriage - and it helps us to understand how difficult it is for some Africans to accept women as they should after menopause. Dickson and Hendriques (1992) give a view on menopause which is very similar to that of some African people when they say the following:

At times knowing what changes to expect does not make it easy to cope with the changes. The changes are viewed as annoying, stressful, and fatiguing. It is very true that sometimes these changes are identified as interfering with usual daily living. In order to articulate that some communities view menopause as a negative experience, some of women [have] even consulted health care providers for treatment. (p. 55)

Africans' sexuality is greatly affected by their attitudes and expectations. First there is a myth in African society that after menopause women are 'past it'. This stems from the exclusive association of sexual activity with reproductive ability: Once fertility is over, sex is irrelevant. It is true that, if a woman had endured sex only because she wanted to conceive, after menopause she would have a sense that she has lost her worth. In corroboration of the statements above, some of the African scholars who have done some research on the issue of menopause are quoted immediately below. Kofong (1992) puts it as follows:

When women grow older in the traditional Bafut society they often gradually lose appetite for conjugal acts. At times they lose it completely and would [sic] not allow their husbands come near them. (p. 52)

According to Kyomo and Selvan (2004:35-36), the Rev. Ngavatula also wrote about the concept of 'adumile', meaning menopause. According to him there are interesting examples of what is believed to happen to older women who act against the taboo of 'no sex after menopause.' The first thing he says is that the stomach of the woman will grow bigger and bigger. Secondly, the seminal fluid accumulated in her 
stomach will flow out through her genital organ, producing an unpleasant odour. Thirdly, it is believed that she will die, but the living dead or ancestors will not accept her in the future world. These fearful prospects and taboos have led women to be guardians of this taboo, and it seems that men are more willing to break them than women. Because of this taboo, men whose wives reach menopause are left with three possibilities: abstaining from sex, getting involved with prostitutes or taking another official or unofficial wife (concubine) (Kyomo \& Selvan 2004:35).

\section{The consequences (abusive side) of menopause in the African context Polygamous marriages and their consequences}

According to Labeodan (2007:45), in many African marriages, a woman cannot overrule her husband if he chooses to have more children. If she does, her husband will obtain another woman. That is in line with Oduyoye's (1995; see also Nasimiyu-Wasike 1995:102) contention:

The female is to be a 'monotheist' while the male acts as a 'polytheist', arrogating to him [sic] the freedom to worship the bodies of several women.' In this way, it would be very easy for a husband to have freedom to marry a second wife because procreative power is very important for the family. (p. 22)

The premise of this article is that it is accepted as a normal custom that, at menopause, the husband is exempted from his obligations towards his wife in order to marry a second wife. Some of the negative effects of polygamous marriages are that the rearing and discipline of children become a problem because of the absence of the father figure, most of whose time is not spent with the children. Khathide (2007:41) also argue that the harsh economic realities of modern times discourage polygamy since housing and education become tremendous challenges for a polygamous husband. This implies that, if the husband opts for a second marriage in the event of his first wife reaching menopause, some of the above-mentioned problems will be unavoidable.

\section{Vulnerability to HIV and AIDS}

As a result of having multiple sex partners, both men and women become unable to protect themselves against unwanted pregnancies and sexually transmitted infections such as STIs and HIV (Labeodan 2007:43). In this case, the husband who opts for another woman for sexual intimacy may become infected with HIV. Although it is clear that there are many different ways through which one can be exposed to HIV and Aids, an extramarital affair is one of the most common ways to become infected. In fact, the ways in which culture and beliefs encourage unequal power and gender relations have been highly debated, and the ways in which unequal power and gender relations increase the vulnerability to infection with HIV have been demonstrated (Mboya 2010:121). In the African context, men (husbands) are the sole providers for their families, and if the head of the family happens to be infected with HIV and dies, his departure will affect the whole family negatively. When the head of the family dies, the family members usually face poverty and the fate of being orphaned.

\section{Endangered self-esteem}

According to Du Toit (1990:3), self-esteem is a product of selfevaluation and other evaluation within the cultural context in which women gain or lose status as they pass through the climacteric years. In other words, the definition and the perception of oneself in some cultures do not depend only on how one sees or perceives oneself but also on how one is perceived by other people in the community. The fact that many African people live very communally and believe in the saying 'I am because we are' makes it easier for one to be deeply affected by what other people are saying about you. The way we live as Africans is shaped by the values and belief system of the community. Self-esteem is built upon trusting oneself. Menstruation is a sign of fertility, whilst a child is a token of authenticity in our society. Hence a loss of the sign of fertility means that a woman may feel a loss of the status and identity that stems from being fertile (Komesaroff et al. 1997:232).

The implication is that the way other people in the surroundings view menopause, particularly those who place a negative connotation on it, makes it an expression of harassment to those who want to feel accepted in the community. Consequently, it debases their self-esteem. Therefore, from a gender-equality point of view, it is my contention that the view of some African cultures on menopause is a cause of concern. This is because women who pass the stage of menopause are viewed as unequal or less worthy by their husbands who tend to view the change negatively.

\section{Women feel they have lost their former importance}

I am in agreement with Voda (1997:5) who believes that menopause has in a sense reduced women to the level of ovaries and uterus, and as such, women have become less important people after menopause in some African contexts. Mills (2011:1) alludes to it as follows: 'Menopausal women, you have served your purpose, now please step aside.' According to Mills, this directly or indirectly indicates that some cultures treat older women as less valuable members of the society. Sigmund Freud held a similar opinion: He based the meaning of a woman's life, or her power, on her ability or inability to bear children. Fundamentally this implies that the lives of postmenopausal women lose their purpose; they become invisible (cf. Mills 2011:1).

I am also of the opinion that this has resulted in the fact that, since women in some African tribes (e.g. Shangaans) are seen mainly as child-bearing vehicles, it becomes very difficult for them to retain their position as important people in society once their role of bearing and rearing children is over. Women 
derive greater meaning from and place greater significance on their reproductive capacity than do men. That is why, according to Labeodan (2007:46), the essence of marriage for all women is to have children. Similarly, Gupta et al. (2010:218) maintain that the physiological, psychological or anatomical effects of menopause are likely to develop emotional stress, usually a feeling of not being fully a woman, not measuring up to others and a sense of shame and inadequacy. This is what most African women, who have developed an attitude of seeing themselves as intended for and married to be childbearers, will feel when they reach menopause.

Du Toit (1990:198) says: 'If a woman has an affair, she is condemned - a man might be forgiven. Men always do it more often, they are always exempted.' This statement sums up exactly to what extent the patriarchal system exempts men, whilst at the same time, it oppresses women. Men's freedom is unlimited, whilst women's freedom is very limited. It is clear from the explanation of this taboo by Kyomo and Selvan that men are left with choices to either have concubines or become involved in prostitution which, in a sense, gives a man much more freedom than a woman. These acts are not expected of women in African cultures, even if the man has problems with sexual performance.

In other words, the interpretation is that rules and regulations are put in place to control women during the menopause, whereas there is nothing to control men. Instead they are rewarded with a free hand to have other sexual partners. From the human rights point of view, this limits a woman's freedom when compared to that of a man. Society does not need to be reminded that the patriarchal system of beliefs and values demonstrates a problem here. The author agrees fully with Martin and Jung (2002:276-268) on their point that this is one of the ways in which patriarchal systems control and suppress women whilst males remain dominant. Women have been taught to cooperate with the male privilege and to support men in their privileged powerful positions, which dominate women.

\section{The subjugation of women}

Vorster (2007:74) points out that the patriarchal supremacy of the man, which is derived from Hebrew society, became evident amongst African societies in that men have the freedom to have more than one wife, a privilege which is not afforded equally to women. This view is echoed in the Sotho idiom: 'Monna ke tshwene, o ja ka motsogo amabedi', meaning 'A man is a baboon, he eats with two hands'. The idea here, according to Masenya (2003:188-189) is that, although married, a man may have other women outside the marital relationship to satisfy his sexual needs.

The African view on menopause opens up the possibility of subjecting women (wives) to unconditional subordination by men. This becomes even clearer from the practice of forcing a woman to agree to her husband marrying a second wife despite the well-known consequences of polygamy in the African context. Kahinga (2007:119) views polygamy as one of the manifestations of oppression of women in various cultures and particularly as depicted in the African cultural context.

Nevertheless, when we consider the fact that women also participate in extramarital relationships, it becomes easier to understand why some of them will be expected to refrain from sexual encounters. According to Mishra (2008:104), the subjugation of women offers both detailed argument and passionate eloquence in opposing the social and legal inequalities commonly imposed upon women by patriarchal culture. The domination of women, the way some decisions are taken against them without the slightest consultation, is a result of sin and not a norm which God has ordained. It exists since the fall of man, from which the unconditional domination of women is derived and normalised (Van der Walt 2008:24).

\section{Pastoral-theological guidelines The need for pastoral counselling}

The author is in agreement with Gerkin (1991:29) that pastoral caregivers are called to give purposive guidance to the people of God. It is also part of the pastoral caregivers' role to intervene and give their assistance in cases where menopause is used to separate husbands and wives. According to King et al. (2005:36), women are relatively more likely to suffer from depression and other psychological diseases for which they should seek physical and mental health care. This in itself indicates the need for some kind of counselling for women during the menopausal transition. Both counselling and medication play significant roles in assisting these women to face the emotional challenges and physical symptoms of menopause. The mood swings or other stresses related to menopause are reasons why counselling would be beneficial in the context of this condition.

Since marriage and family therapists are specifically trained to assist women with marital issues, they are sensitive to the spiritual issues that may accompany marital conflict. It is therefore advisable that, as soon as women start noticing any symptoms of menopause, they should consult their family doctor who will then advise and treat them accordingly. That is why King et al. (2005:38) ask the question: 'Besides counselling, where else can women find hope in the many challenges and stressful moods of menopause and the midlife?' Both husband and wife (in case of a married couple) need to be aware of the changes and their effect on their sexual life after menopause.

One important change with which the pastoral caregiver should help the couple entails the fact that the excitement phase of sexual arousal requires longer foreplay since the lubrication takes longer. This might create tension between the couple since it might be interpreted as rejection or a lack of response due to a lack of interest. Pastoral counselling is important to prepare the couple to accommodate these changes brought on by the physical changes of the body and to avoid unnecessary quarrels and misunderstandings 
between them. In other words, the couple should know that arousal after menopause will take longer than before, and thus patience and accommodation of the change should be well explained and understood (Millette \& Hawkins 1983:66).

\section{Therapy}

Eskin (2007:304) mentions a need for 'Bach flower remedies' which he calls 'a therapeutic system that uses specially prepared plant infusions to balance physical and emotional disturbances.' According to him, the practice of gentle stretching, exercises for breath control and meditation as mind-body interventions will help women during their menopause. Gupta et al. (2010:218) maintain that the very first step in treating a female orgasmic disorder, which makes women feel unworthy and prone to emotional distress, is education. Since many women with this problem believe that they are the only sufferers, they need reassurance that, like many other women, they can still lead a normal sexual life. Therapy for couples will be useful in cases where there may be underlying issues between the partners or where the woman may benefit from a deeper exploration of any emotional blocks to orgasm. Sex toys and vibrators can also be helpful as aids in this condition. Practising Kegel's pelvic floor exercises to strengthen the pubococcygeal muscles is also recommended by Gupta et al. (2010:218).

According to Eskin (2007:133), women in the menopause often do very well on anti-thyroid medication given for six months to a year and then discontinued. A longer period of time may be needed for this repetitive therapy after an unsuccessful hiatus. The spontaneous success from medical therapy is satisfying since both radiation and surgery may cause damage to the thyroids (Eskin 2007:132). Three types of therapy that will be helpful for women in menopause are sequential therapy, continuous combined therapy and oestrogen-only therapy (Gupta et al. 2010:230)

\section{Sexual intercourse not intended only for procreation}

Waruta and Kinothi (2000:102) agree with Mbiti on the fact that 'marriage and procreation in African communities are a unity, without procreation, marriage is incomplete'. It is within this framework of mind that sexual intercourse is viewed by most traditional Africans. This traditional belief that sexual intercourse is intended for procreation only needs to be challenged and corrected pastorally. It is the duty of the church through its pastors and leaders to teach people that sexual intercourse is not intended only for procreation. There are other reasons why it needs not be stopped just because the woman has entered the menopausal stage. Church leaders can play a very significant role in this matter because, in the African context, church leaders are crucially important in influencing people's viewpoints concerning matters of sex and marriage. The reason is that, in normal African circumstances, the views of the church leader are highly esteemed in the community and general society (Mboya 2010:125). Marriage counsellors need to teach people that they should continue enjoying this beautiful gift from God even after the child-bearing period is over. If sexual intercourse can still be performed after menopause, there is no reason why women should be barred from engaging in it, whilst men are allowed to continue enjoying it outside of marriage.

\section{Premarital counselling should be used to change the view of future generations}

According to information of the Mayo Clinic (Mayo Clinic Staff n.d.), premarital counselling is a type of therapy that helps couples prepare for marriage. It can also help young people to identify weaknesses that could become bigger problems during marriage. Piver (n.d.) articulates that real expectations and real knowledge of oneself and your partner to face the inevitable challenges of a committed relationship are included in pre-marital counselling. Premarital counselling can be used to limit and change some of the traditional African views on marriage. The danger inherent in the African practice of regarding women as inferior beings (Mashau 2006:51), which goes as far as deciding to exempt a wife from sexual encounters after menopause, can be prevented if the premarital counselling considers teaching young couple about it beforehand. In other words, premarital counselling can contribute significantly to illuminating problems like these if it is used to treat marriage problems holistically by preparing young people for possible marriage challenges. Lastly, Msomi (2008:210) indicated that clinical pastoral education should fit its context, and therefore, it is important to indicate that such counselling should understand and accommodate African traditional views on marriage and sex.

\section{Family doctors should be consulted regularly}

Maboea (2002), in his book entitled The influence of life-giving power in the African traditional religion, indicates that, in times of problems and illness, traditional Africans prefer traditional healers and ancestral veneration rather than medical doctors. Although this is not the focus of this study, it is this challenge that the pastoral caregivers should be ready to face in encouraging as well as convincing church members of the importance of also consulting medical doctors.

Pastoral caregivers should advise people or couples who are facing menopause to consult a family medical doctor. It is incumbent upon the family doctor to help the couple with medical guidance in order to avoid unnecessary misunderstandings and quarrels in the family. This is because, for instance, only doctors can confirm after thorough tests whether the woman has indeed reached menopause since there can also be other health-related causes for the cessation of a woman's periods. It is only after consultation that both the couple and the pastoral caregiver may know whether their sexual relationship after menopause is healthy or not. Then the pastoral caregiver could help to encourage the couple to have sexual intercourse at their own will if it does not endanger their health. 


\section{The role of the relationship between husband and wife}

Pastoral caregivers may help couples to realise the important role of the marital relationship during the course of their marriage until the menopausal stage. In this way, the couple need to realise that sex and intimacy is more than attempting to fall pregnant. In other words, the husband and wife need to care for one another even after menopause. The author agrees with Hocking and Hocking (1984:112) when they argue that 'intimate friendship' does not necessarily imply sexual relationship. They went on to emphasise that a relationship in marriage is more important perhaps than sexual intercourse itself when saying:

Husbands and wives should be intimate friends. Dishonesty with each other only hinders the development of intimate friendship. There ought to be full acceptance and forgiveness. You should be able to share anything and everything with your marital partner. (Hocking \& Hocking 1984:112)

This is the beauty of marriage which should not be confused with sex. Part of this is also articulated by Wiersbe (2002:50) when indicating that people (couples in this context) should care for each other. This means that caring for each other in marriage must not be disturbed or replaced by sexual issues. It should be the relationship that comes before sex and not the opposite.

\section{Conclusion}

It should be clear from the preceding discussion that problems arising at menopause do not stem from the menopause itself, but from people's cultural attitudes towards it. It is also true that the African view of menopause brings with it negative aspects like reducing women to mere child-bearing objects whose self-esteem and sexual roles in marriage are thereby undermined and even shattered. The author is in full agreement with Chauke (2003:120-140) and Masenya (2003:116-124) who indicate that culture and religious beliefs are still used amongst African people to promote gender and power relations, most of which disadvantage women. In this article, the author has been at pains to highlight the consequences of this tradition as well as to give some guidelines on how pastoral caregivers can play a role in eliminating problems arising from this traditional perception which relegates women to the position of mere objects after menopause.

\section{Acknowledgements}

\section{Competing interests}

The author declares that he has no financial or personal relationship(s) which may have inappropriately influenced him in writing this article.

\section{References}

Baloyi, M.E., 2001, 'Counselling Christian Shangaans on choosing a marriage partner', MEd dissertation, University of North West, Potchefstroom.

Baloyi, M.E., 2010, 'Lobolo in the African community: A critical evaluation', Journal of Theology and Religion in Africa 34(1), 50-70.

Baloyi, M.E., 2011, 'Critical reflection on polygamy in the African Christian context', paper delivered at the Conference on Law, Gender and Transformation at the University of Limpopo, Turfloop Campus, Sovenga, 03 September - 03 October 2010.
Burman, S., 1991, 'Illegitimacy and the African family in a changing South Africa', Acta Juridica, 36-51.

Chauke, E., 2003, 'Theological challenges and ecclesiological responses to women experiencing HIV/AIDS and faith communities', in I.A. Phiri, B. Haddad \& M Masenya (eds.), African women, HIV/AIDS and faith communities, pp. 128-148, Cluster Publications, Pietermaritzburg.

Collins, A., 2011, 'Sociocultural issues in menopause', viewed 03 October 2011, from http://www.hawaii.edu/hivandaids/women

Dickson, A. \& Hendriques, N., 1992, Menopause: The woman's view, Quartet, London.

Du Toit, B.M., 1990, Aging and menopause among Indian South African women, State University of New York, Albany.

Eskin, B.A., 2007, The menopause - Endocrinologic basis and management options, Informa healthcare, London.

Gathogo, J.M., 2007, 'The use of ancestral resources in combating HIV and AIDS: Mundurume's task', Journal of Constructive Theology 13(1), 5-24.

Gerkin, C.V., 1991, Prophetic pastoral practice - A Christian vision of life together, Abingdon Press, Nashville.

Gupta, S., Holloway, D. \& Kubba, A., 2010, Oxford handbook of women's health nursing, Oxford University Press, Oxford.

Hocking, D. \& Hocking, C., 1984, Good marriages take time: Bad marriages take more time, Harvest House Publishers, Oregon.

Kahinga, J.K., 2007, 'Polygamy: A pastoral challenge to the church in Africa', African Ecclesial Review, 119-147.

Khathide, A.G., 2007, Bone of my bones: Building marriages that work in Africa, AcadSA, Kempton Park.

Kimathi, G., 1994, Your marriage and family, IRS, Potchefstroom

King, E., Hunter, M.H. \& Harris, J.R., 2005, Dealing with the psychological and spiritual aspects of menopause: Finding hope in the midlife, The Haworth Pastoral Press, New York.

Komesaroff, P., Rothfield, P. \& Daly, J. (eds.), 1997, Reinterpreting menopause Cultural and philosophical issues, Routledge, New York.

Kofon, N.E., 1992, Polygyny in pre-Christian Bafut and new moral theological perspective, Peter Lang, Frankfurt.

Kyomo, A.A. \& Selvan, S.G., 2004, Marriage and family in African Christianity, Acton, Nairobi.

Labeodan, H.A., 2007, 'The Yoruba belief system and its impact on women's reproductive health', Journal of Constructive Theology 13(1), 39-55.

Maboea, S.I., 2002, The influence of life-giving power in the African tradition religion and the Zionist churches in Soweto - A comparative study, CB Powell Bible Centre, Pretoria.

Martin, L. \& Jung, P., 2002, Taking charge of the change - A holistic approach to the three phases of menopause, Delmar Thomson Publication, Colombia.

Masenya, M., 2003, 'Trapped between two "canons": African-South African Christian women in the HIV/AIDS era', in I.A. Phiri, B. Haddad \& M. Masenya (eds.), African women, HIV/AIDS and faith communities, pp. 3-20, Cluster Publications, Pietermaritzburg.

Mashau, T.D., 2006, Unlocking the mystery of marriage - Issues in premarital counselling', V \& R Printing Works, Pretoria.

Mayo Clinic Staff, (n.d.), 'Premarital counselling', viewed on 16 April 2012, from http:// www.mayoclinic.com

Mboya, R., 2010, 'A local church's holistic response to HIV/AIDS', Southern African Journal of Missiology 38(1), 121-141.

Millette, B.M. \& Hawkins, J.B.W., 1983, Women and the menopause: A book for and about women and the climacteric, Reston Publishing Company, Reston.

Mills, M.D., 2011, 'A look at menopause across cultures', viewed 16 May 2011, from http://www.womentowomen.co/menopasue/menopauseacrosscultures.aspx

Mishra, N., 2008, Women law against violence and abuse, Pearl Books, New Delhi.

Msomi, V.V., 2008, Ubuntu contextual African pastoral care and counselling, CB Powell Bible Centre, Pretoria.

Nasimiyu-Wasike, A., 1995, Polygamy: A feminist critique, in M.A. Oduyoye \& R.A.K. Musimbi (eds.), The will to arise: Women, tradition and the church in Africa, $\mathrm{pp}$ 101-118, Orbis, Maryknoll.

Nhlapo, T.R., 1991, The African family and women's rights: Friends or foes? Acta Juridica, 135-146.

Oduyoye, M.A., 1995, Women and Ritual in Africa, in M.A. Oduyoye \& R.A.K. Musimb (eds.), The will to arise: Women, tradition and the church in Africa, pp. 135-146, Orbis, Maryknoll.

Peil, M. \& Oyeneve, O., 1998, Consensus: Conflict and change, East African Educational Publishers, Nairobi.

Piver, S., (n.d.), 'Is premarital counselling or education for you?', viewed 16 April 2012, from http://www.wedalert.com.

Van der Walt, B.J., 2008, The Bible as an eye-opener on the position of women, IRS, Potchefstroom.

Voda, A.M., 1997, Menopause, me and you: The sound of women pausing, Haworth Publishers, Harrington Park.

Vorster, N., 2007, Restoring human dignity in South Africa: Christian anthropology in a new dispensation, $\mathrm{V} \& \mathrm{R}$ Printing Works, Pretoria.

Waruta, D.W. \& Kinoti, H.W. (eds.), 2000, Pastoral care in African Christianity, Acton Press, Nairobi.

Wiersbe, W.W., 2002, Caring people: Learning to live with and help one another, Baker Books, Grand Rapids. 